Systematic Review

\title{
The Role of the Nurse Unit Manager Function on Nursing Work Performance: A Systematic Review
}

\author{
Fitriyanti Patarru', Basilius Yosepfus Weu, Febrina Secsaria Handini and Heryyanoor \\ Heryyanoor
}

Faculty of Nursing, Universitas Airlangga, Surabaya, East Java, Indonesia

\begin{abstract}
Introduction: The role of Nurse Unit Manager is to improve the nurses' performance in the context of their professional services. This role consists of planning, organizing, actuating and controlling. The aim of this systematic review was to determine the influence of the nurse unit manager's management functions related to the nurses' performance.

Methods: The literature search was conducted in the PubMed, Scopus, ProQuest, Science Direct and SAGE databases with the keywords 'head nurses', 'management function' and 'nurse performance'. The articles were reviewed using the inclusion criteria, which was that the title and abstract was in accordance with the desired topic, that the article aimed to analyze the influence of the nurse unit manager's management functions related to the nurses' performance and that it was explained in English. The exclusion criteria were that the title, abstract and purpose of the article was not in accordance with the topic of focus. The search identified 15 relevant journals from the 276.303 articles published between 2014 and 2019 .
\end{abstract}

Results: The results indicate a significant relationship exists between the role of the nurse unit manager and nursing work performance.

Conclusion: To improve the management function of the nurse unit manager, it is necessary to conduct training for the nurse unit manager to allow them to better understand the functions and role of the nurse unit manager.

\section{ARTICLE HISTORY}

Received: December 26, 2019

Accepted: December 31, 2019

\section{KEYWORDS}

nurse unit manager; nursing work performance; role

\section{CONTACT}

Fitriyanti Patarru'

$\triangle$ fitriyanti.patarru-

2018@fkp.unair.ac.id

$\equiv$ Faculty of Nursing, Universitas

Airlangga, Surabaya, Indonesia

Cite this as: Patarru', F Patarru', F., Weu, B. Y., Handini, F.S. \& Heryyanoor, H. (2019). The Role of the Nurse Unit Manager Function on Nursing Work Performance: A Systematic Review. Jurnal Ners, 14(3si), 231-235. doi:http://dx.doi.org/10.20473/jn.v14i3(si).17108

\section{INTRODUCTION}

The evaluation of the nurses' activity when providing nursing care for the patients is the most important factor when taking care of the patients and their satisfaction regarding the care is an important indicators (Fateme \& Enayatollah, 2016). Nursing, as a service field, is highly labor-intensive. This makes nursing management particularly challenging because of the wide variety of experience and educational backgrounds of the employees in the health care setting. The type of work, as well as the workers themselves, challenge the nurse manager to create the kind of environment that facilitates quality nursing practices. The nurse unit manager has specific responsibilities to the organization and to the staff. The staff, in turn, have responsibilities to the organization and to their manager. The beginning nurse will contribute to the success of the unit's efficiency by being aware of the manager's role (Rashed, Al Torky, \& Morsey, 2015). The phenomenon that occurs in several hospitals is that there are still many nurse unit managers who have not implemented management functions, thus affecting the performance of the team leader and having a further impact on the quality of the nursing services.

The principles of management can be categorized into the four major functions of planning, organizing, leading and controlling (the P-O-L-C). The four functions are highly integrated when they are carried out in the day-to-day realities of running an organization. Planning is the function of management that involves setting objectives and determining a 
course of action for achieving those objectives. It is required that the managers are aware of the environmental conditions faced by their organization and that they are able to forecast future conditions. Organizing is the function of management that involves developing an organizational structure and allocating human resources to ensure the accomplishment of the objectives. Leading involves the social and informal sources of influence used to inspire the actions taken by others. If the managers are effective leaders, then they will inspire their subordinates to enthusiastically exert their efforts to achieve the common organizational objectives. Controlling involves ensuring that performance does not deviate from the standards set (Miri, Mansor, Alkali, \& Chikaji, 2014).

All managers, irrespective of where or what they manage, need to develop several competencies that will enable them to effectively perform the four generic functions of planning, organizing, leading and controlling. The head nurses' performance plays an important role in the successful operation of the hospital. The identification and prioritization of managerial competencies required for the supervisors and for the evaluation of their performance on this basis is necessary (Moghaddam et al., 2019). In general, job performance relates to an organizations' success. However, it is more than simply one person doing their job well because they want to. Performance is an organizational behavior. In a work environment that is strained by financial constraints and organizational changes, nurse leaders and managers remain accountable for the success of the organization as a whole. Performance evaluation analyses the managers' skills and performance by determining their strengths and weaknesses. Performance evaluation also counts as a tool for developing managerial skills (H. M. ousav. Isfahani, Aryankhesal, \& Haghani, 2015). The aim of this systematic review is to determine the influence of the management functions of the nurse unit manager on the performance of the nurses.

\section{MATERIALS AND METHODS}

\section{Design}

A systematic review was prepared following a statement based on the Preferred Reporting Items for Systematic Reviews and Meta-analyses (PRISMA). This involved: 1) the identification of the literature through searching the databases using the selected keywords, 2) the screening of the literature based on both the inclusion and exclusion criteria, 3) the eligibility of the literature in full text form and 4) the final chosen articles being included in the systematic review.

\section{Search strategies and inclusion criteria}

The literature search was carried out on several databases such as PubMed, Scopus, Proquest, Science Direct and SAGE with the journal search resulting in 276.303 articles. The search was done by entering the keywords 'management function', 'nurse unit

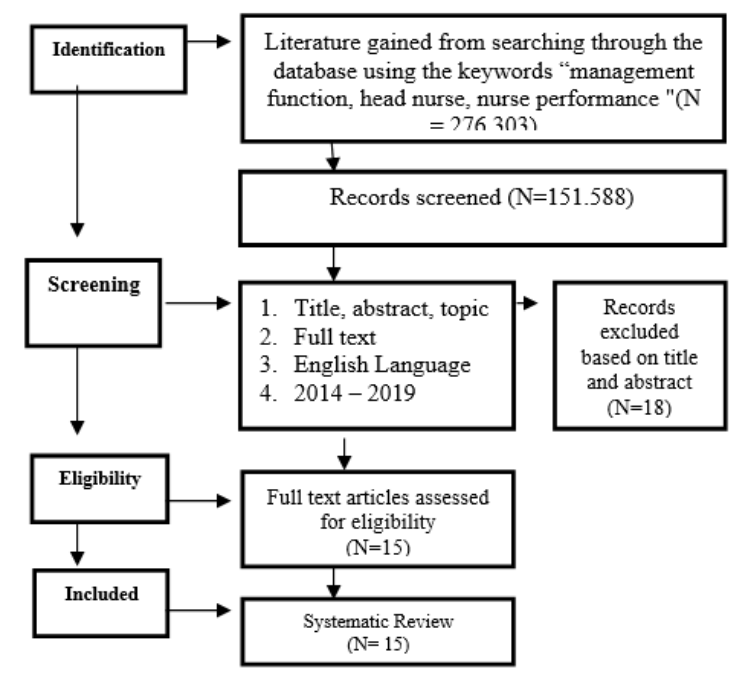

\section{Figure 1. PRISMA flow chart}

manager' and 'performance'. The year limit used was 2014 - 2019, with the inclusion criteria being that the title and abstract were in accordance with the desired topic. The article had to aim to determine the effect of the management function of the nurse unit manager on the performance of the nurses and the article must be original research that has been reviewed and explained in English. The search resulted in 15 articles that corresponded to the criteria. The exclusion criteria were if the results of the study did not explain the approximate relationship between the role of the management functions of the nurse unit manager and the nurse's performance, if the title and abstract did not match the desired topic and if the article was not explained in English.

\section{RESULTS}

This systematic review used 15 articles published with 3,059 respondents in total. The independent variable was the nurse unit manager's management function. The dependent variable was the nurses' performance. Several studies have been previously conducted that support the role of the nurse unit manager. There were several variables found in the discussion about the management function of nurse unit managers and in relation to the performance of the nurses. The results showed that the nurse unit manager's management function was evaluated using three different instruments. Three management function questionnaires were used to measure the management functions of the head nurse managers. The three categories included 34 responsibilities: 1) Clinical practice with 11 items, 2) Managerial with 17 items and 3) Educational with 6 items. Nursing activity analysis was the observation of the nurses done by monitoring the actual time of patient care every 15 minutes for 6 days during the period of the data collection. This was used to calculate the productivity of the staff nurses (Rashed et al., 2015).

The questionnaires that were distributed to the nurses also used the planning, organizing, staffing, actuating and controlling (POSAC) approach (Rina 
Karmila et al., 2018). This was in the form of a qality assessment and validity tool used in correlational studies. The study was focused on the role of first line nurse managers FLNMs (management and clinical skills) (Miri et al., 2014). The data was collected via a checklist of the nurse unit manager's managerial skills based on the BARS principles. We found there to be a significant relationship between the nurse unit manager's management functions as the independent variable with nurse performance as the dependent variable. In this systematic review, the results of several articles were obtained. Overall, 27 managerial competencies required for nurse unit manager were identified and categorized in the 4 main categories relating to management functions, namely planning, organizing, leadership and controlling (Moghaddam et al., 2019).

There is a correlation between the nurse unit manager's management functions and nursing productivity in the medical unit, surgical unit, postoperative ICU and casualty intensive care unit in Assiut University Hospital. This was found using a structured interview questionnaire about the management functions of first-line nurse managers. The results of the present study revealed that, there is a statistically significant relation between the staffing element and the quality of patient care. About two thirds of the head nurses were applying most activities on an acceptable level as the staffing and controlling process, while they were unacceptable for planning, organizing and directing generally. This was analyzed using a self-administered questionnaire for the head nurses and observation checklists for the patients (Elmoghith et al., 2014). In the planning function, it was found that there was no specific policy regarding the implementation of the nursing shift handover. This was obtained based on the results of documentation studies and interviews with the head of nursing. The results of the interviews with the head nurse from 8 inpatient wards also showed there to be a lack of guidance and standard operating procedures regarding patient handover between nursing shifts. This resulted in the unstructured implementation of the nursing shift handover. This was assessed using a questionnaire distributed to the nurses using the planning, organizing, staffing, actuating, and controlling (POSAC) approach. The first questionnaire was about the nurses' perceptions of the ward heads associated with surrender and implementation and the second questionnaire was related to the implementation of the nursing shift by the nurses (Rina Karmila et al., 2018).

From the 15 articles reviewed, the results show that the role of the management function of the nurse unit manager has an influence on the performance of the nurses. The management functions of the nurse unit manager include planning, organizing, staffing, actuating and controlling. To see whether there is an effect of the management function from the nurse unit manager on the nurses' performance, this was measured using a questionnaire that was distributed to the implementing nurses to assess the competence of the nurse unit manager. From this article, it was also found that not all of the nurse unit managers performed their roles and functions properly.

\section{DISCUSSION}

This systematic review focuses on the discussion of the role of the management functions of the nurse unit manager in influencing nurse performance. From the 15 articles found, not all of the nurse unit managers performed their functions properly. There were still those who have not implemented their functions fully which can have a negative impact on the performance of the nurses in the hospitals.

The head nurses' roles is that of the front line firefighting service of nursing care. It is the most challenging nursing role that involves a detailed description of the tasks involved. The head nurse has three main areas that constitute their role. These are patient care management to ensure that the patient's total needs are met, staff management to utilize, guide, evaluate and correct the staff nurses in their nursing practice and unit management to ensure its smooth running to fulfill the hospital goals (Rashed et al., 2015). Managerial competencies can be categorized in four main functions (including planning, organizing, leadership and control) as previously identified (Moghaddam et al., 2019). Planning practices include drawing up plans. This is the first and perhaps most important step in the management process and the findings showed that the practice was almost universal (95 percent). Only three ( 5 percent) participants did not use the approach in their wards. In one study, the managerial level of the managers was low. These results follow the same conclusion.

This indicates that the managerial skills of the managers are an important factor for improving the work proficiency. A lack of these skills causes disorder in the organization. This study also emphasizes the importance of developing managerial skills by the nursing managers (H. M. ousav. Isfahani et al., 2015). Supervision or direction is important to improve the staff motivation when implementing an activity so then their performance becomes better. Supervision activities can increase the employee's motivation, enthusiasm and confidence, causing the employees to be more driven and to improve their performance. Supervision is important to improve motivation, spirit and the performance of nurses in terms of performing activities including handover (Rina Karmila et al., 2018). In general, these findings suggest that there is an important relationship between nursing leadership and nurse performance. Nurse leaders play a key role in fostering autonomy, building relationships and managing resources, which are the very factors that nurses state they require to effectively perform. Based on Carpenter's management principles, the roles involve duties and skills. These can be clustered into three categories planning, organizing and leadership (Miri et al., 2014). The nurse leaders both indirectly and directly 
influence their subordinates' performance and thereby the goals of the healthcare organization that they represent.

The limitation in this systematic review was the number of articles that are still lacking according to the topic, as well as due to variations in the instruments and measurements.

\section{CONCLUSION}

The findings from the 15 articles show that there is an influence from the role of the management function of the head of the room on the performance of the implementing nurses. Management functions can be categorized into four main functions: planning, organizing, leading/actuating and controlling (P-O-L$\mathrm{C} / \mathrm{P}-\mathrm{O}-\mathrm{A}-\mathrm{C})$. Nursing management plays a key role in today's healthcare organizations, thus there is a need for a further discussion of the nurse managers' leadership and management competencies. In fact, head nurses in hospitals not only need to accomplish their clinical practices but they are also required to carry out the administrative tasks that are entrusted to them as part of their management responsibilities. In order to carry out the task effectively, the nurse unit manager must have competence that can guide well so as to improve the nurse's performance. The responsibility of the nurse unit manager in improving nurse performance is by carrying out the management function of the nurse unit manager with full responsibility in term of leading and guiding the nurses. This can improve the performance of the nurses by having a positive impact on their satisfaction with the hospital services. They should also conduct training for the nurse unit manager to allow them to better understand the competencies.

\section{REFERENCES}

Barkhordari-Sharifabad, M., Ashktorab, T., \& Atashzadeh-Shoorideh, F. (2018). Ethical competency of nurse leaders: A qualitative study. Nursing https://doi.org/10.1177/0969733016652125

Denker, A. L., Sherman, R. O., Hutton-Woodland, M., Brunell, M. Lou, \& Medina, P. (2015). Florida nurse leader survey findings: Key leadership competencies, barriers to leadership, and succession planning needs. Journal of Nursing Administration.

https://doi.org/10.1097/NNA.00000000000002 22

Divshali, M. \&Firouuzkouhi. (2015). Evaluation of scales and barriers of managerial performance of head nurses based on BARS performance evaluation model in Rasht, 2011. (January).

Elmoghith, N. G. A. B. D., Sc, M., Hamouda, S. I., Sc, D. N., Ibrahim, S. A., \& Sc, D. N. (2014). The Effect of Nursing Management Process Applied by Head Nurses on Quality of Patient Care in the Main Mansoura University Hospital. 82(1), 583-590.

Fateme, K., \& Enayatollah, S. (2016). The study of nurses ' performance from the viewpoints of head nurses in the special and general wards of the instructional hospitals of Zahedan in 2015. (9), 212-216.

Huang, C. Y., Weng, R. H., \& Chen, Y. T. (2016). Investigating the relationship among transformational leadership, interpersonal interaction and mentoring functions. Journal of Clinical https://doi.org/10.1111/jocn.13153

Nursing.

Isfahani, H. M., Aryankhesal, A., \& Haghani, H. (2015). The Relationship Between the Managerial Skills and Results of " Performance Evaluation " Tool Among Nursing Managers in Teaching Hospitals of Iran University of Medical Science. 7(2), 38-43. https://doi.org/10.5539/gjhs.v7n2p38

Isfahani, H. M. ousav., Aryankhesal, A., \& Haghani, H. (2015). The relationship between the managerial skills and results of "performance evaluation "tool among nursing managers in teaching hospitals of Iran University of Medical Science. Global Journal of Health Science. https://doi.org/10.5539/gjhs.v7n2p38

Kantanen, K., Kaunonen, M., Helminen, M., \& Suominen, T. (2017). Leadership and management competencies of head nurses and directors of nursing in Finnish social and health care. Journal of Research in Nursing. https://doi.org/10.1177/1744987117702692

Kovačič, H., \& Rus, A. (2015). Leadership Competences in Slovenian Health Care / Vodstvene Kompetence V Slovenskem Zdravstvu. Slovenian Journal of Public Health. https://doi.org/10.1515/sjph-2015-0002

Lee, M., \& Chung, K. (2016). A Study on the Classification and Development of Pattern Designs Represented in Luggage. Journal of the Korean Society of Costume. https://doi.org/10.7233/jksc.2016.66.1.135

Matlakala, M. C., Bezuidenhout, M. C., \& Botha, A. D. H. (2014). Challenges encountered by critical care unit managers in the large intensive care units. Curationis. https://doi.org/10.4102/curationis.v37i1.1146

Miri, S. A., Mansor, N. N. A., Alkali, A., \& Chikaji, A. (2014). The role of first line nurse manager. Review of European Studies. https://doi.org/10.5539/res.v6n4p31

Moghaddam, N. M., Jame, S. Z. B., Rafiei, S., Sarem, A. A., Ghamchili, A., \& Shafii, M. (2019). Managerial competencies of head nurses: A model and assessment tool. British Journal of Nursing. https://doi.org/10.12968/bjon.2019.28.1.30

Rashed, S. A. E., Al Torky, M. A. M., \& Morsey, S. M. (2015). Performance of head nurses management functions and its effect on nurses' productivity at Assiut University Hospital. IOSR Journal of Nursing and Health Science (IOSR-JNHS). https://doi.org/10.9790/1959-04523849

Rina Karmila et al., R. K. et al. . (2018). Description of Nursing Shift Handover Implementation in One of Provincial Public Hospitals in DKI Jakarta Province. International Journal of Medicine and 
JURNAL NERS

Pharmaceutical Sciences, 8(2), 39-48.

https://doi.org/10.24247/ijmpsapr20187 